\title{
Nanostructured iron(III)-copper(II) binary oxide: A novel adsorbent for enhanced arsenic removal from aqueous solutions
}

\author{
Gaosheng Zhang ${ }^{a, b, *}$, Zongming Ren ${ }^{a, b}$, Xiwang Zhang ${ }^{c}$, Jing Chen ${ }^{a, b}$ \\ ${ }^{a}$ Key Laboratory of Coastal Zone Environmental Processes, Yantai Institute of Coastal Zone Research (YIC), \\ Chinese Academy of Sciences (CAS), 17th Chunhui Road, Yantai, Shandong 264003, China \\ b Shandong Provincial Key Laboratory of Coastal Zone Environmental Processes, YICCAS, 17th Chunhui Road, \\ Yantai, Shandong 264003, China \\ ${ }^{\mathrm{c}}$ School of Chemical Engineering, Building 74, College Rd, University of Queensland, Brisbane, QLD 4072, Australia
}

\section{A R T I C L E I N F O}

Article history:

Received 3 April 2012

Received in revised form

12 September 2012

Accepted 12 November 2012

Available online 22 March 2013

\section{Keywords:}

Fe-Cu binary oxide

Sorption

Arsenate

Arsenite

Regeneration

\begin{abstract}
A B S T R A C T
To obtain a highly efficient and low-cost adsorbent for arsenic removal from water, a novel nanostructured $\mathrm{Fe}-\mathrm{Cu}$ binary oxide was synthesized via a facile co-precipitation method. Various techniques including BET surface area measurement, powder XRD, SEM, and XPS were used to characterize the synthetic $\mathrm{Fe}-\mathrm{Cu}$ binary oxide. It showed that the oxide was poorly crystalline, 2-line ferrihydrite-like and was aggregated with many nanosized particles. Laboratory experiments were performed to investigate adsorption kinetics, adsorption isotherms, $\mathrm{pH}$ adsorption edge and regeneration of spent adsorbent. The results indicated that the $\mathrm{Fe}-\mathrm{Cu}$ binary oxide with a $\mathrm{Cu}$ : Fe molar ratio of 1:2 had excellent performance in removing both $\mathrm{As}(\mathrm{V})$ and $\mathrm{As}$ (III) from water, and the maximal adsorption capacities for $\mathrm{As}(\mathrm{V})$ and $\mathrm{As}(\mathrm{III})$ were 82.7 and $122.3 \mathrm{mg} / \mathrm{g}$ at $\mathrm{pH} 7.0$, respectively. The values are favorable, compared to those reported in the literature using other adsorbents. The coexisting sulfate and carbonate had no significant effect on arsenic removal. However, the presence of phosphate obviously inhibited the arsenic removal, especially at high concentrations. Moreover, the $\mathrm{Fe}-\mathrm{Cu}$ binary oxide could be readily regenerated using $\mathrm{NaOH}$ solution and be repeatedly used. The $\mathrm{Fe}-\mathrm{Cu}$ binary oxide could be a promising adsorbent for both $\mathrm{As}(\mathrm{V})$ and $\mathrm{As}(\mathrm{III})$ removal because of its excellent performance, facile and low-cost synthesis process, and easy regeneration.
\end{abstract}

() 2013 Elsevier Ltd. All rights reserved.

\section{Introduction}

Arsenic, a ubiquitous element found in the environment, is well-known and extensively concerned with high toxicity and carcinogenicity. It is introduced into the water and groundwater through a combination of natural processes such as weathering reactions, dissolution of minerals and biological activity as well as through anthropogenic activities such as mining, agriculture and manufacturing (Cullen and Reimer, 1989; Smedley and Kinniburgh, 2002). Elevated arsenic levels in groundwater near human populations have been reported in many countries and regions throughout the world, which

\footnotetext{
* Corresponding author. Key Laboratory of Coastal Zone Environmental Processes, Yantai Institute of Coastal Zone Research (YIC), Chinese Academy of Sciences (CAS), 17th Chunhui Road, Yantai, Shandong 264003, China. Tel./fax: +86 05352109139.

E-mail addresses: gszhang@yic.ac.cn, zgs77@126.com (G. Zhang). 0043-1354/\$ - see front matter @ 2013 Elsevier Ltd. All rights reserved. http://dx.doi.org/10.1016/j.watres.2012.11.059
} 
poses a significant threat to human health (Mandal and Suzuki, 2002; Smedley and Kinniburgh, 2002). To abate health problems associated with arsenic in drinking water, the World Health Organization (WHO) recommended a more stringent limit of $10 \mu \mathrm{g} \mathrm{L}^{-1}$ as the maximum permissible arsenic level. Therefore, developing economical, effective and reliable treatment technique for arsenic removal from groundwater is critical and has gained considerable attention in recent years.

Arsenic occurs mostly in two inorganic forms as oxyanions of arsenate $[\mathrm{As}(\mathrm{V})]$ and arsenite $[\mathrm{As}(\mathrm{III})]$ in groundwater, with the latter being more toxic, soluble, and mobile (Goddington, 1986). Under oxidizing conditions, negatively charged $\mathrm{H}_{2} \mathrm{AsO}_{4}^{-}$is the major arsenic species at $\mathrm{pH}$ lower than 6.9, while $\mathrm{HAsO}_{4}^{2-}$ is dominant at higher $\mathrm{pH}$. For arsenite, the uncharged $\mathrm{H}_{3} \mathrm{AsO}_{3}$ dominates at $\mathrm{pH}$ lower than 9.0 under reducing conditions (Yan et al., 2000; Smedley and Kinniburgh, 2002). Various treatment techniques such as coagulation/precipitation (Scott et al., 1995), ion-exchange (Kartinen and Martin, 1995), sorption (Jang et al., 2006; Zhang et al., 2007a) and membrane processes (Kartinen and Martin, 1995; Waypa et al., 1997) have been developed and employed for arsenic removal. Due to its simplicity, high efficiency and cost-effectiveness, sorption processes are regarded as the most promising methods and largely used for arsenic removal from water and wastewater (Jang et al., 2006; .Sharma and Sohn, 2009).

Different sorbents, including natural and synthetic materials have been extensively investigated to remove arsenic from aqueous solutions (Mohan and Pittman, 2007). Recently, increasing attention has been focused on metal oxide sorbents such as iron (Raven et al., 1998; Dixit and Hering, 2003), aluminum (Lin and Wu, 2001; Patra et al., 2012), titanium (Pena et al., 2005; Jegadeesan et al., 2010; Xu et al., 2010), manganese (Lenoble et al., 2004; Lafferty et al., 2010), and zirconium (Hristovski et al., 2008; Hang et al., 2012). Among these iron (hydr)oxides were the mostly studied because of their high affinity to arsenic species, low cost and environmental friendliness.

Most recently, developing composite sorbents containing two or more metal oxides have gained considerable attention, since the composite not only inherits the advantages of parent oxides but shows obviously synergistic effect. For instances, Zhang et al. (2005) developed an Fe-Ce bimetal oxide sorbent, which has a much higher $\mathrm{As}(\mathrm{V})$ adsorption capacity than the individual Ce and Fe oxide. Zhang et al. (2007a) prepared an Fe-Mn binary oxide sorbent, exhibiting a greater enhancement in both $\mathrm{As}(\mathrm{V})$ and $\mathrm{As}(\mathrm{III})$ removal. Gupta and Ghosh (2009) reported the synthesis and use of an Fe-Ti binary mixed oxide for arsenic sorption. Li et al. (2010) synthesized a $\mathrm{Ce}-\mathrm{Ti}$ oxide sorbent with high efficiency at both $\mathrm{As}(\mathrm{V})$ and As(III) removal. Ren et al. (2011) found that an Fe-Zr binary oxide prepared in their laboratory had high sorption capacity towards arsenic.

Recently, it was reported that cupric oxide was an effective sorbent for both $\mathrm{As}(\mathrm{V})$ and $\mathrm{As}(\mathrm{III})$ removal over a wide $\mathrm{pH}$ range and performed well in the presence of competing anions (Martinson and Reddy, 2009). They attributed the effective arsenic removal by $\mathrm{CuO}$ to its high point of zero charge of approximate 9.4 (Yoon et al., 1979). Although CuO sorbent is effective in removing arsenic from water, it is not economical to use pure $\mathrm{CuO}$ as sorbent, due to its relatively high cost (The current price of powder $\mathrm{CuO}(98 \%)$ is US $\$ 6000-8800 / \mathrm{Ton}$, while the iron oxide (96\%) is US $\$ 500-1000 / T o n)$. Therefore, to develop low-cost, effective and reliable alternatives for arsenic removal is still necessary. To combine $\mathrm{CuO}$ with iron oxides to produce a novel composite sorbent may reduce the cost and maintain the high performance simultaneously. However, to our best knowledge, no information is available on the synthesis of $\mathrm{Fe}-\mathrm{Cu}$ binary oxides and their performance for arsenic removal from water.

Thus, in this study, a facile chemical precipitation method was developed to synthesize $\mathrm{Fe}-\mathrm{Cu}$ binary oxides at room temperature. The main objectives of this research were (1) to optimize the $\mathrm{Cu} / \mathrm{Fe}$ molar ratio in the $\mathrm{Fe}-\mathrm{Cu}$ binary oxides; (2) to characterize the prepared $\mathrm{Fe}-\mathrm{Cu}$ binary oxides with a variety of techniques; (3) to evaluate their arsenic adsorption capacity and investigate sorption kinetics as well as the influences of solution $\mathrm{pH}$ and co-existing ions on arsenic sorption, and finally (4) to study regeneration and reusability of spent adsorbent.

\section{Materials and methods}

\subsection{Materials}

All chemicals are analytical grade and were used without further purification. Reaction vessels (glass) were cleaned with $1 \% \mathrm{HNO}_{3}$ and rinsed several times with deionized water before use. $\mathrm{As}(\mathrm{V})$ stock solution was prepared with deionized water using $\mathrm{NaHAsO}_{4} \cdot 7 \mathrm{H}_{2} \mathrm{O}$ and $\mathrm{As}$ (III) stock solution was prepared with $\mathrm{NaOH}$ solution using $\mathrm{As}_{2} \mathrm{O}_{3}$. $\mathrm{As}(\mathrm{V})$ and $\mathrm{As}(\mathrm{III})$ working solutions were freshly prepared by diluting arsenic stock solutions with deionized water.

\subsection{Synthesis of $\mathrm{Fe}-\mathrm{Cu}$ binary oxide sorbents}

A series of Fe-Cu binary oxides were synthesized at 0:1, 1:10, $1: 5,1: 3,1: 2,1: 1.5,1: 1$, and 1:0 Cu:Fe molar ratios at room temperature. The $\mathrm{Fe}-\mathrm{Cu}$ binary oxides were prepared according to the following procedure: A certain amount of ferric chloride hexahydrate $\left(\mathrm{FeCl}_{3} \cdot 6 \mathrm{H}_{2} \mathrm{O}\right)$ and copper(II) sulfate pentahydrate $\left(\mathrm{CuSO}_{4} \cdot 5 \mathrm{H}_{2} \mathrm{O}\right)$ were dissolved in $400 \mathrm{ml}$ deionized water. The Cu:Fe molar ratio was adjusted to the predetermined value via changing the amount of $\mathrm{CuSO}_{4} \cdot 5 \mathrm{H}_{2} \mathrm{O}$ or $\mathrm{FeCl}_{3} \cdot 6 \mathrm{H}_{2} \mathrm{O}$ added. Under vigorous magnetic-stirring, sodium hydroxide solution $(3 \mathrm{~mol} / \mathrm{L}$ ) was added dropwise to raise the solution $\mathrm{pH}$ to around 7.5. The formed suspension was continuously stirred for $1 \mathrm{~h}$, aged at room temperature for $4 \mathrm{~h}$ and then washed several times with deionized water. The suspension was then filtrated and dried at $55^{\circ} \mathrm{C}$ for $24 \mathrm{~h}$. The dry material was crushed and stored in a desiccator for use. The obtained material appeared in the form of fine powder.

\subsection{Characterization of $\mathrm{Fe}-\mathrm{Cu}$ binary oxide}

The composition of the 1:2 $\mathrm{Fe}-\mathrm{Cu}$ binary oxide was determined by classical chemical analysis. A definite amount of the oxide was treated with $10 \%$ oxalic acid solution. The oxide was reduced and dissolved by the oxalic acid and formed $\mathrm{Fe}^{3+}$ and 
$\mathrm{Cu}^{2+}$ entered into solution. The content of $\mathrm{Cu}^{2+}$ and $\mathrm{Fe}^{3+}$ in the solution was determined using an ICP-OES (Optima 7000 DV, Perkin Elmer Co. USA).

$\mathrm{X}$-ray diffraction (XRD) analysis was carried out on a Rigaku D/Max-3A diffractometer using Ni-filtered copper $\mathrm{K} \alpha$ 1 radiation. The morphology of the particles was observed using a field scanning electron microscope (FESEM) (Hitachi S-4800, Japan). The specific surface area was measured via nitrogen adsorption using the BET method with a surface area analyzer (Nova, 2000e; Quantachrome Instruments, USA). X-ray photoelectron spectra (XPS) were collected on an ESCA-Lab-220i-XL spectrometer with a monochromatic Al $\mathrm{K} \alpha \mathrm{X}$-ray source $(1486.6 \mathrm{eV})$. C1s peaks were used as an inner standard calibration peak at $284.7 \mathrm{eV}$. For wide scan spectra, an energy range of $0-1100 \mathrm{eV}$ was used with pass energy of $80 \mathrm{eV}$ and step size of $1 \mathrm{eV}$. The high-resolution scans were conducted according to the peak being examined with pass energy of $40 \mathrm{eV}$ and step size of $0.05 \mathrm{eV}$. The XPS results were collected in binding energy forms and fitted using a nonlinear least-square curve fitting program (XPSPEAK41 Software).

The point of zero charge (PZC) was measured via a slightly modified method described by Kinniburgh et al. (1975). The Fe-Cu binary oxide powder was suspended in $0.01 \mathrm{M} \mathrm{NaNO}_{3}$ for $24 \mathrm{~h}$, after which the rate of $\mathrm{pH}$ change with time was very slow. $50 \mathrm{ml}$ of suspension was then adjusted to various $\mathrm{pH}$ values with $\mathrm{NaOH}$ or $\mathrm{HNO}_{3}$ solution. After agitation for 60 min for equilibrium, the initial $\mathrm{pH}$ was measured; then $1.5 \mathrm{~g}$ of $\mathrm{NaNO}_{3}$ was added to each suspension to bring final electrolyte concentration to about $0.45 \mathrm{M}$. After an additional $12 \mathrm{~h}$, the final $\mathrm{pH}$ was measured. The results, plotted as $\Delta \mathrm{pH}$ (final $\mathrm{pH}$ initial $\mathrm{pH}$ ) against final $\mathrm{pH}$, yielded the $\mathrm{pzc}$ as the $\mathrm{pH}$, at which $\Delta \mathrm{pH}$ equals to 0 .

\subsection{Batch sorption and desorption experiments}

Sorption kinetics, sorption isotherm and the effects of $\mathrm{Cu}: \mathrm{Fe}$ molar ratio, solution $\mathrm{pH}$ and coexisting anions on arsenic sorption were determined in batch sorption experiments.

To determine the optimal Cu:Fe molar ratio, batch tests were carried out by adding $10 \mathrm{mg}$ of prepared sorbents into $150-\mathrm{mL}$ glass vessels, containing $50 \mathrm{ml}$ of $14.6 \mathrm{mg} / \mathrm{L}$ arsenic solution. The $\mathrm{pH}$ of the solutions was adjusted every four hours with dilute $\mathrm{HNO}_{3}$ or/and $\mathrm{NaOH}$ solution to around $\mathrm{pH}$ 7.0 during shaking process. The equilibrium $\mathrm{pH}$ was measured and the supernatant was filtered through a $0.45 \mu \mathrm{m}$ membrane after the solutions were mixed for $24 \mathrm{~h}$. Then, the residual arsenic concentration in the supernatants was determined.

For sorption kinetics, defined amount of As(V) or As(III) stock solution was added in a 1000 -ml glass vessel containing $1000 \mathrm{ml} 0.01 \mathrm{M} \mathrm{NaNO}_{3}$ solution, to make $10 \mathrm{mg} / \mathrm{L}$ of initial arsenic concentration. The solution $\mathrm{pH}$ was adjusted to $7.0 \pm 0.1$ by adding $0.1 \mathrm{M} \mathrm{HNO}_{3}$ and/or $\mathrm{NaOH}$ and then $1: 2$ $\mathrm{Fe}-\mathrm{Cu}$ binary oxide was added to obtain a $0.2 \mathrm{~g} / \mathrm{L}$ suspension. The suspension was mixed by magnetic-stirring, and the $\mathrm{pH}$ was maintained at $7.0 \pm 0.1$ throughout the experiment by addition of the acid and base solutions. In the whole process, only several drops of acid or base were added into the solution and the total volume was no more than $0.5 \mathrm{ml}$, which did not significantly influence the arsenic sorption. Approximately
$5 \mathrm{ml}$ aliquots were taken from the suspension at certain time intervals. The samples were filtered through a $0.45 \mu \mathrm{m}$ membrane filter and analyzed for arsenic.

To investigate the influence of $\mathrm{pH}$ on arsenic sorption, experiments were carried out by adding $10 \mathrm{mg}$ of $1: 2 \mathrm{Fe}-\mathrm{Cu}$ binary oxide into $150-\mathrm{mL}$ glass vessels, containing $50 \mathrm{ml}$ of $10 \mathrm{mg} / \mathrm{L}$ arsenic solution. The $\mathrm{pH}$ of the solutions was adjusted every four hours with dilute $\mathrm{HNO}_{3}$ or/and $\mathrm{NaOH}$ solution to designated values during sorption process. The equilibrium $\mathrm{pH}$ was measured and the supernatant was filtered through a $0.45 \mu \mathrm{m}$ membrane after the solutions were mixed for $24 \mathrm{~h}$. Then, the residual arsenic concentration in the supernatants was determined. Additionally, to evaluate the leaching of $\mathrm{Fe}$ and $\mathrm{Cu}$ from the sorbent at different $\mathrm{pHs}$, the Fe and $\mathrm{Cu}$ concentrations in the supernatant solutions were also measured using ICP-OES.

For sorption isotherms, the experiments were performed at $\mathrm{pH}$ 7.0. The $\mathrm{pH}$ of suspensions was adjusted with $0.1 \mathrm{M}$ of $\mathrm{NaOH}$ and $\mathrm{HNO}_{3}$ during the experiment. Initial arsenic concentration varied from $5 \mathrm{mg} / \mathrm{L}$ to $60 \mathrm{mg} / \mathrm{L}$. In each test, $10 \mathrm{mg}$ of 1:2 Fe-Cu binary oxide was loaded in the $100-\mathrm{mL}$ glass vessel and $50 \mathrm{ml}$ of solution containing differing amounts of arsenic were then added to the vessel. The vessels were shaken on an orbit shaker at $200 \mathrm{rpm}$ for $24 \mathrm{~h}$ at $24 \pm 1{ }^{\circ} \mathrm{C}$. Then, all samples were filtered by a $0.45 \mu \mathrm{m}$ membrane filter and analyzed for arsenic.

The influence of commonly coexisting anions in water such as sulfate, bicarbonate, and phosphate on the removal of arsenic was investigated by adding sodium sulfate, sodium bicarbonate and sodium phosphate to $10 \mathrm{mg} / \mathrm{L}$ of arsenic solution, respectively. The anion concentrations ranged from 5 to $100 \mathrm{mg} / \mathrm{L}$. The solution $\mathrm{pH}$ was adjusted to $7.0 \pm 0.1$. A defined amount (10 mg) of 1:2 Fe-Cu binary hydrous oxide was added and the solutions were agitated at $200 \mathrm{rpm}$ for $24 \mathrm{~h}$ at $24 \pm 1{ }^{\circ} \mathrm{C}$. After filtration by a $0.45 \mu \mathrm{m}$ membrane filter, the concentration of residual arsenic was analyzed using ICP-OES.

Four cycles of adsorption and desorption were carried out to evaluate the reusability of the prepared binary oxide. For the adsorption test, $0.5 \mathrm{~g} \mathrm{Fe}-\mathrm{Cu}$ binary oxide was added into a vessel containing $1 \mathrm{~L}$ solution with $25 \mathrm{mg} / \mathrm{L}$ arsenic, the solution was stirred for $24 \mathrm{~h}$ and maintained at about $\mathrm{pH}$ 7.0, and then the adsorbent was separated and collected from the solution. The residual arsenic concentration was measured using the ICP-OES. For the desorption test, the arseniccontaining $\mathrm{Fe}-\mathrm{Cu}$ binary oxide was added into a $100 \mathrm{ml}$ $0.5 \mathrm{M} \mathrm{NaOH}$ solution. The mixture was stirred for $6 \mathrm{~h}$ and then regenerated adsorbent was separated from the $\mathrm{NaOH}$ solution. After washing and drying, it was used in the next adsorption-desorption cycle.

\subsection{Analytical methods}

Arsenic was measured using an inductively coupled plasma atomic emission spectroscopy machine (ICP-OES, Optima 7100 DV, Perkin Elmer Co. USA). Prior to analysis, the aqueous samples were acidified with concentrated $\mathrm{HCl}$ in an amount of $1 \%$, and stored in acid-washed glass vessels. All samples used in our analysis were analyzed within $24 \mathrm{~h}$ after collection. 

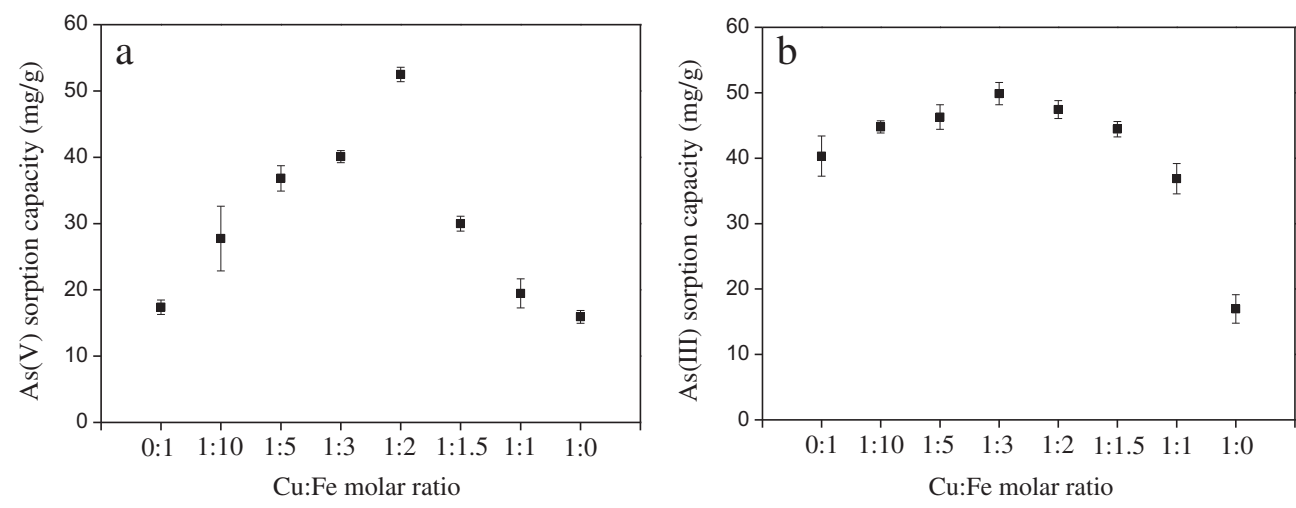

Fig. 1 - Effect of Cu:Fe molar ratio on (a) $\mathrm{As}(\mathrm{V})$ and (b) As(III) sorption by Fe-Cu binary oxide. Arsenic initial concentration $=14.6 \mathrm{mg} / \mathrm{L}$, sorbent dose $=200 \mathrm{mg} / \mathrm{L}, \mathrm{pH}=7.0 \pm 0.1, \mathrm{~T}=25 \pm 1{ }^{\circ} \mathrm{C}$.

\section{Results and discussion}

\subsection{Effect of Cu:Fe molar ratio on arsenic sorption}

To determine the optimal $\mathrm{Cu}$ :Fe molar ratio, a series of $\mathrm{Fe}-\mathrm{Cu}$ binary oxide adsorbents with different $\mathrm{Cu}: F e$ molar ratios from 0:1 to 1:0, were synthesized and tested for arsenic sorption. The results are shown in Fig. 1 . As(V) sorption by the $\mathrm{Fe}-\mathrm{Cu}$ binary oxide increases obviously with an increase in $\mathrm{Cu}$ :Fe molar ratio and reaches a maximum of approximately $53 \mathrm{mg} \mathrm{g}^{-1}$ when the ratio is 1:2. Then, $\mathrm{As}(\mathrm{V})$ sorption decreases significantly with further increase in $\mathrm{Cu}: F e$ molar ratio. The
$\mathrm{As}(\mathrm{V})$ sorption capacity decreases to $20 \mathrm{mg} \mathrm{g}^{-1}$ at a $\mathrm{Cu}: \mathrm{Fe}$ molar ratio of 1:1. This value is very close to that of pure iron oxide (17.4 $\mathrm{mg} \mathrm{g}^{-1}$ at $\mathrm{Cu}$ :Fe molar ratio of 0:1). At Cu:Fe molar ratio of 1:0, namely for the pure copper oxide, $\mathrm{As}(\mathrm{V})$ sorption capacity further fell to about $16 \mathrm{mg} \mathrm{g}^{-1}$. Theoretically, if no synergy effect occurred between iron oxide and copper oxide, the $\mathrm{As}(\mathrm{V})$ sorption capacity of 1:2 Fe-Cu binary oxide should be $16.9 \mathrm{mg} \mathrm{g}^{-1}$, which is far less than the real value of $53 \mathrm{mg} \mathrm{g}^{-1}$. For As(III), similar phenomena were observed, except that maximal As(III) sorption occurred at 1:3 Fe-Cu binary oxide and variation in sorption capacity was less remarkable than that of $\mathrm{As}(\mathrm{V})$. These results suggest that the combination of copper oxide with iron oxide results in a
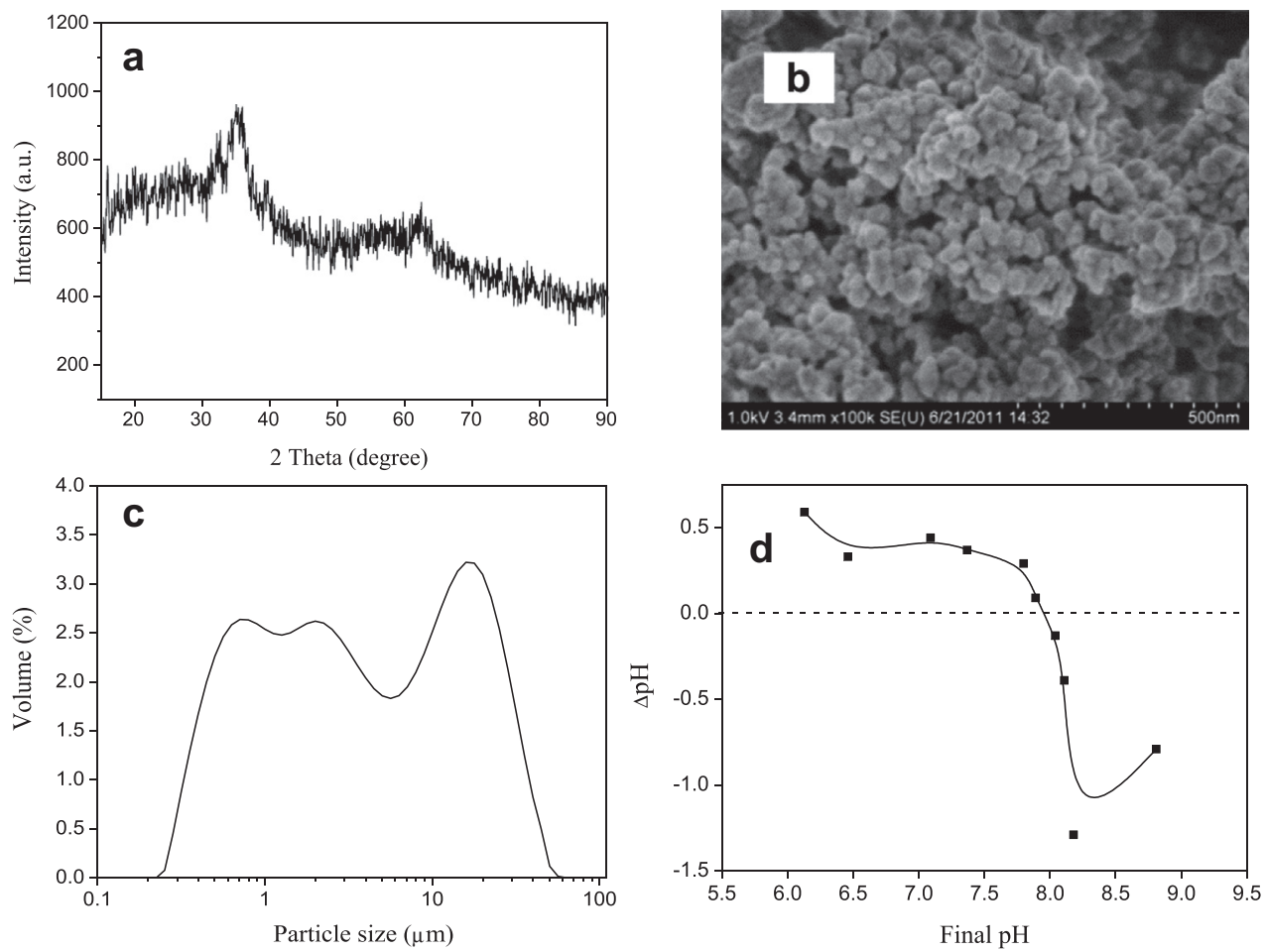

Fig. 2 - (a) XRD diffraction pattern, (b) FESEM image, (c) particle size distribution, and (d) point of zero charge (pzc) of Fe-Cu binary hydrous oxide. 

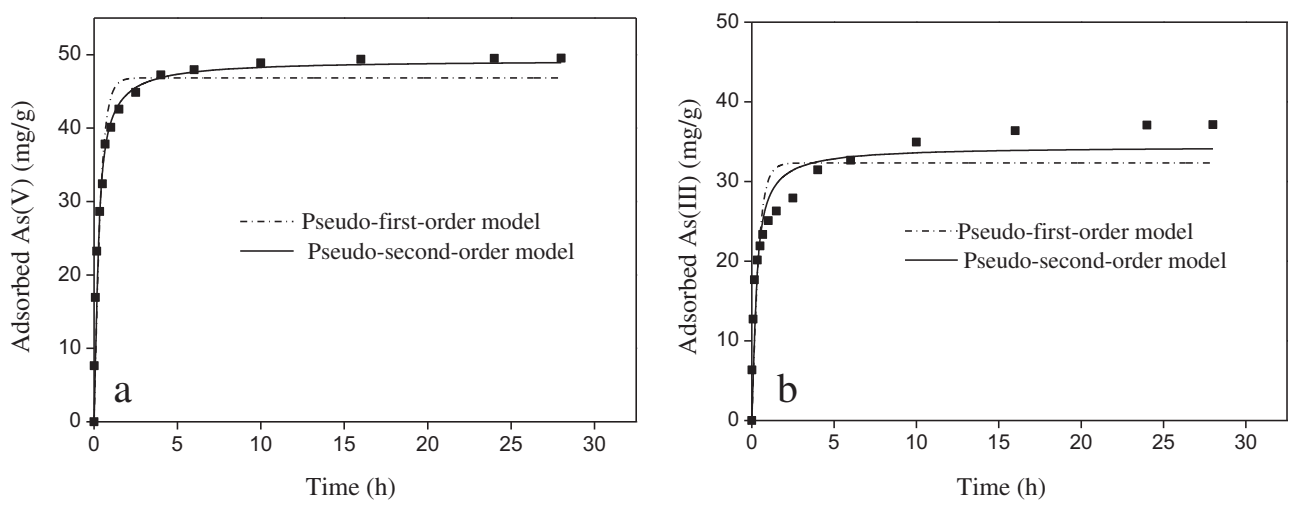

Fig. 3 - Kinetics of (a) $\mathrm{As}(\mathrm{V})$ and (b) As(III) sorption onto $\mathrm{Fe}-\mathrm{Cu}$ binary oxide at $\mathrm{pH}=7.0 \pm 0.1$. Arsenic initial concentrations $=10 \mathrm{mg} / \mathrm{L}$, adsorbent dose $=200 \mathrm{mg} / \mathrm{L}$ and $\mathrm{T}=25 \pm 1{ }^{\circ} \mathrm{C}$.

significant improvement in arsenic sorption. And the Cu:Fe molar ratio is a key factor influencing the sorption capacity of the $\mathrm{Fe}-\mathrm{Cu}$ binary oxide.

Considering comprehensively effectiveness and cost, the $\mathrm{Fe}-\mathrm{Cu}$ binary oxide with the $\mathrm{Cu}$ :Fe molar ratio of 1:2 was chosen as feasible sorbent and was detailed examined in the following sections.

\subsection{Characterization of 1:2 Fe-Cu binary oxide}

The chemical analysis of the prepared 1:2 Fe-Cu binary oxide showed that the $\mathrm{Cu}: \mathrm{Fe}$ molar ratio of the bulk was $0.491 \pm 0.012$. X-ray diffraction pattern of the oxide is illustrated in Fig. 2a. It demonstrates two broad peaks at approximately 35.1 and $62.2^{\circ}$, respectively, which are similar to those of poorly ordered 2-line ferrihydrite (Schwertmann and Cornell, 2000; Ren et al., 2011). This indicates that the prepared $\mathrm{Fe}-\mathrm{Cu}$ binary oxide is amorphous and 2-line ferrihydrite-like. Fig. $2 b$ illustrates the SEM image of the oxide particles, showing that they are aggregates formed by small nanograins (around $50 \mathrm{~nm}$ ). The distribution of particle size of the powdered oxide is depicted in Fig. 2c, indicating that main particle size of this binary oxide is in the range of $0.3-40 \mu \mathrm{m}$. The amorphous $\mathrm{Fe}-\mathrm{Cu}$ binary hydrous oxide has a high BET surface area of $282 \mathrm{~m}^{2} / \mathrm{g}$ and a pore volume of $0.31 \mathrm{~cm}^{3} / \mathrm{g}$. Pore size distribution (PSD) of this oxide estimated by employing BJH (Barrett-Joyner-Halenda) method is shown in Fig. S1. The PSD pattern suggests that the pore is relatively uniform in size with an average pore size of $4.3 \mathrm{~nm}$.

The value of point of zero charge (PZC) of the Fe-Cu binary oxide is approximate 7.9 (Fig. 2d). The PZC of pure ferrihydrite is about pH 7.4 (Zhang et al., 2012) and that of $\mathrm{CuO}$ is pH 9.4 (Yoon et al., 1979). Obviously, the incorporation of $\mathrm{CuO}$ with iron oxide makes the composite a higher PZC than that of pure ferrihydrite.

\subsection{Sorption kinetics}

The rate of arsenic sorption onto the $\mathrm{Fe}-\mathrm{Cu}$ binary oxide was investigated by batch experiments. Fig. 3 shows the change of adsorbed arsenic as a function of contact time. As shown in Fig. 3, initial sorption of both $\mathrm{As}(\mathrm{V})$ and $\mathrm{As}(\mathrm{III})$ was very rapid. After $1 \mathrm{~h}$ of contact with $\mathrm{Fe}-\mathrm{Cu}$ binary oxide, about $80 \%$ and $70 \%$ of equilibrium sorption capacity were achieved for $\mathrm{As}(\mathrm{V})$ and As(IIII), respectively. In the following period, the arsenic sorption slowed down and over $98 \%$ of equilibrium sorption capacity was reached for both $\mathrm{As}(\mathrm{V})$ and $\mathrm{As}(\mathrm{III})$ after a reaction of $16 \mathrm{~h}$. The time taken to reach the equilibrium is about $24 \mathrm{~h}$. Therefore, a reaction time of $24 \mathrm{~h}$ was chosen for all other batch experiments. For whole sorption process, As(III) sorbed more slowly than $\mathrm{As}(\mathrm{V})$. Similar results were observed for sorption of $\mathrm{As}(\mathrm{V})$ and $\mathrm{As}(\mathrm{III})$ by pure cupric oxide (Martinson and Reddy, 2009).

The pseudo-first-order model and pseudo-second-order model were employed to describe the kinetic data. The mathematical representations of the models are given in Eqs. (1) and (2), respectively.

$$
\begin{aligned}
& \frac{\mathrm{d} q_{\mathrm{t}}}{\mathrm{dt}}=k_{1}\left(q_{\mathrm{e}}-q_{\mathrm{t}}\right) \\
& \frac{\mathrm{d} q_{\mathrm{t}}}{\mathrm{dt}}=k_{2}\left(q_{e}-q_{\mathrm{t}}\right)^{2}
\end{aligned}
$$

where $q_{\mathrm{e}}$ and $q_{\mathrm{t}}$ are the adsorption capacities $(\mathrm{mg} / \mathrm{g}$ ) of the adsorbent at equilibrium and at time $t(h)$, respectively; $k_{1}\left(\mathrm{~h}^{-1}\right)$ and $k_{2}(\mathrm{~g} \mathrm{mg} / \mathrm{h})$ are the related adsorption rate constants.

Table 1 - Adsorption rate constant obtained from pseudo-first-order model and pseudo-second-order model.

Arsenic species

Pseudo-first-order model pseudo-second-order model

\begin{tabular}{lccccrr} 
& $k_{1}\left(\mathrm{~h}^{-1}\right)$ & $q_{\mathrm{e}}(\mathrm{mg} / \mathrm{g})$ & $R^{2}$ & $k_{2}(\mathrm{~g} / \mathrm{mg} \cdot \mathrm{h})$ & $q_{\mathrm{e}}(\mathrm{mg} / \mathrm{g})$ & $R^{2}$ \\
\hline As(V) & 2.952 & 46.8 & 0.949 & 0.099 & 49.3 & 0.989 \\
As(III) & 2.492 & 41.5 & 0.933 & 0.094 & 43.7 & 0.982 \\
\hline
\end{tabular}



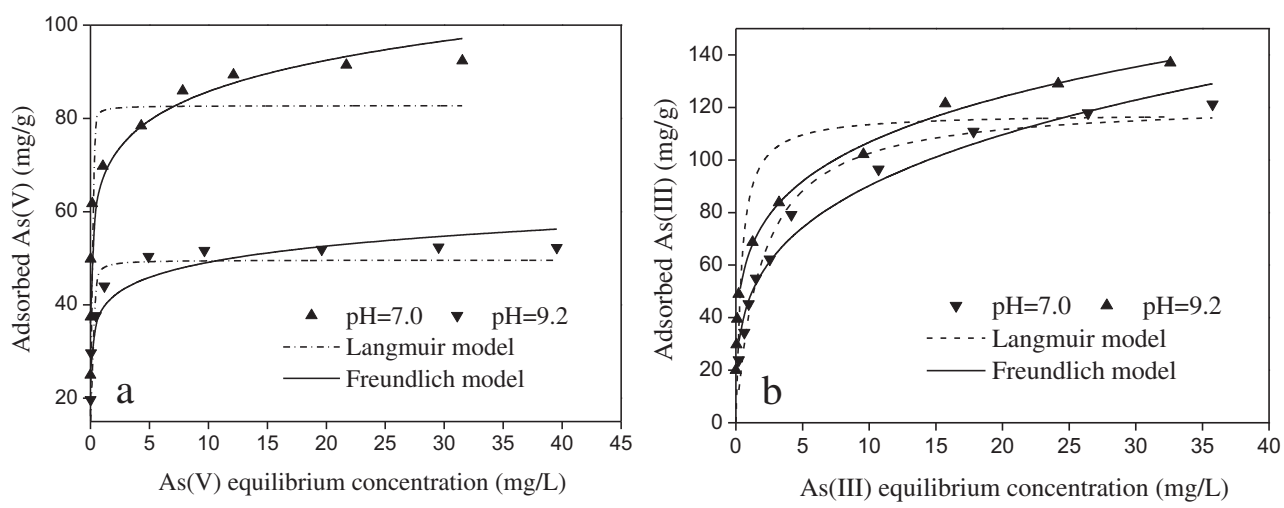

Fig. 4 - Adsorption isotherms for (a) As(V) and (b) As(III) by Fe-Cu binary oxide at two pHs and T $=25 \pm 1{ }^{\circ} \mathrm{C}$; ( - ) Langmuir model and $(-)$ Freundlich model.

The rate constants obtained from pseudo-first-order and pseudo-second-order models are listed in Table 1. For both $\mathrm{As}(\mathrm{V})$ and $\mathrm{As}(\mathrm{III})$, the experimental data fitted better with pseudo-second-order model than pseudo-first-order model, which indicates that the adsorption process might be chemisorption.

\subsection{Sorption isotherms}

The arsenic sorption capacities of the Fe-Cu binary oxide at two pHs were evaluated using the isotherms and presented in Fig. 4. It can be seen that the $\mathrm{Fe}-\mathrm{Cu}$ binary oxide has high sorption capacity for both $\mathrm{As}(\mathrm{V})$ and $\mathrm{As}(\mathrm{III})$. For $\mathrm{As}(\mathrm{V})$, its sorption capacity reduced greatly, when solution $\mathrm{pH}$ increased from 7.0 to 9.2. But for As(III), the increase in $\mathrm{pH}$ slightly enhanced its sorption. In addition, at low equilibrium concentration, the oxide is more effective in removing $\mathrm{As}(\mathrm{V})$ than As(III). For example, the As(V) adsorption capacity is as high as $62 \mathrm{mg} / \mathrm{g}$ and $37 \mathrm{mg} / \mathrm{g}$ at $\mathrm{pH} 7.0$ and equilibrium concentration of $152 \mathrm{ppb}$ and $9.7 \mathrm{ppb}$, respectively. While, the As(IIII) adsorption capacity is about 49 and $20 \mathrm{mg} / \mathrm{g}$ at $\mathrm{pH} 9.2$ and equilibrium of $208 \mathrm{ppb}$ and $6.8 \mathrm{ppb}$, respectively. However, it has higher sorption capacity for As(III) than that of $\mathrm{As}(\mathrm{V})$ at higher equilibrium concentration. These results indicate that the sorption of $\mathrm{As}(\mathrm{V})$ and $\mathrm{As}(\mathrm{III})$ might be dominated by different mechanisms.

Both Langmuir and Freundlich models were used to describe the adsorption isotherms. The Langmuir equation and Freundlich equation are represented as Eqs. (3) and (4), respectively. $q_{e}=\frac{q_{\max } b C_{e}}{1+b C_{e}}$

$q_{\mathrm{e}}=K_{\mathrm{F}} C_{\mathrm{e}}^{n}$

where $q_{\mathrm{e}}$ is the amount of arsenic adsorbed on the solid phase $(\mathrm{mg} / \mathrm{g}), C_{\mathrm{e}}$ is the equilibrium arsenic concentration in solution phase $(\mathrm{mg} / \mathrm{L}), b$ is the equilibrium adsorption constant related to the affinity of binding sites $(\mathrm{L} / \mathrm{mg}), q_{\max }$ is the maximum amount of the arsenic per unit weight of adsorbent for complete monolayer coverage, $K_{F}$ is roughly an indicator of the adsorption capacity and $n$ is the heterogeneity factor which has a lower value for more heterogeneous surfaces.

The adsorption constants obtained from the isotherms are presented in Table 2. As shown in Table 2, higher regression coefficient suggests that the Freundlich model is more suitable for describing the sorption behavior of arsenic by $\mathrm{Fe}-\mathrm{Cu}$ binary oxide than Langmuir model. The Langmuir model assumes that adsorption occurs on a homogeneous surface. A heterogeneous surface of the Fe- $\mathrm{Cu}$ binary oxide may be formed because of the simultaneous presence of cupric oxide and iron oxide in the binary oxide. The Freundlich model describes sorption where the sorbent has a heterogeneous surface with sorption sites that have different sorption energies. The maximal sorption capacities for $\mathrm{As}(\mathrm{V})$ and $\mathrm{As}(\mathrm{III})$ calculated from Langmuir model are $82.7 \mathrm{mg} / \mathrm{g}$ and $122.3 \mathrm{mg} / \mathrm{g}$, respectively. Such high capacity indicates that prepared $\mathrm{Fe}-\mathrm{Cu}$ binary oxide is very effective for both $\mathrm{As}(\mathrm{V})$ and $\mathrm{As}(\mathrm{III})$ removal. A comparison has been made between the prepared $\mathrm{Fe}-\mathrm{Cu}$ binary oxide and previously reported sorbents for

Table 2 - Langmuir and Freundlich isotherm parameters for As(V) and As(III) sorption on Cu-Fe binary oxide at two pHs.

Langmuir model

\begin{tabular}{lcccccc}
\hline As species and $\mathrm{pH}$ & $q_{\mathrm{m}}(\mathrm{mg} / \mathrm{g})$ & $K_{\mathrm{L}}(\mathrm{L} / \mathrm{mg})$ & $R^{2}$ & & $K_{\mathrm{F}}(\mathrm{mg} / \mathrm{g})$ & $R^{2}$ \\
\hline As(V) pH 7.0 & 82.7 & 71.40 & 0.850 & 66.8 & 0.108 \\
As(V) pH 9.2 & 49.6 & 27.02 & 0.861 & 39.2 & 0.946 \\
As(III) pH 7.0 & 122.3 & 0.517 & 0.967 & 47.25 & 0.098 & 0.281 \\
As(III) pH 9.2 & 117.7 & 2.675 & 0.819 & 64.86 & 0.972 \\
\hline
\end{tabular}


Table 3 - Comparison of maximum arsenic sorption capacities for different adsorbents ${ }^{a}$

\begin{tabular}{|c|c|c|c|c|}
\hline Adsorbent & $\begin{array}{c}\text { As con. range } \\
(\mathrm{mg} / \mathrm{L})\end{array}$ & $\begin{array}{c}\text { Max. As(III) } \\
\text { adsorption } \\
\text { capacity (mg/g) }\end{array}$ & $\begin{array}{c}\text { Max. As(V) } \\
\text { adsorption } \\
\text { capacity }(\mathrm{mg} / \mathrm{g})\end{array}$ & Ref \\
\hline CuO nanoparticles & $0-100$ & $26.9(\mathrm{pH} 8.0)$ & $22.6(\mathrm{pH} 8.0)$ & Martinson and Reddy, 2009 \\
\hline Doughnut-like CuO & $0-90$ & $4.7(4.0)$ & - & Cao et al., 2007 \\
\hline Copper(II) oxide & $0.5-1$ & $1.08(7.0)$ & - & Goswami et al., 2012 \\
\hline Nano- $\mathrm{TiO}_{2}$ & $0-130$ & 99.0 (pH 7.0) & - & Xu et al., 2010 \\
\hline $\mathrm{Fe}-\mathrm{Zr}$ binary oxide & $0-40$ & $120.0(\mathrm{pH} \mathrm{7.0)}$ & 46.1 (pH 7.0) & Ren et al., 2011 \\
\hline Fe-Mn binary oxide & $0-40$ & $100.4(\mathrm{pH} 6.9)$ & 53.9 (pH 6.9) & Zhang et al., 2007b \\
\hline NHITO & $5.0-250$ & $85.0(\mathrm{pH} 7.0)$ & $14.3(\mathrm{pH} 7.0)$ & Gupta and Ghosh, 2009 \\
\hline $\mathrm{Al}_{2} \mathrm{O}_{3} / \mathrm{Fe}(\mathrm{OH})_{3}$ & $7.5-135 \mathrm{mmol}$ & $9.0(\mathrm{pH} 6.6)$ & $36.7(\mathrm{pH} 7.2)$ & Hlavay and Polyák, 2005 \\
\hline MBOP & 1.0 & $16.9(7.0)$ & - & Dhoble et al., 2011 \\
\hline $\mathrm{Fe}-\mathrm{Cu}$ binary oxide & $0-60$ & $122.3(\mathrm{pH} 7.0)$ & $82.7(\mathrm{pH} 7.0)$ & Present study \\
\hline
\end{tabular}

a $\mathrm{pH}$ is shown in parentheses.

arsenic sorption (Table 3). The analytical result of comparison shows that the prepared $\mathrm{Fe}-\mathrm{Cu}$ binary oxide outperforms remarkably many other sorbents. This indicates that the $\mathrm{Fe}-\mathrm{Cu}$ binary oxide is a rather promising alternative for arsenic removal.

\subsection{Influence of $\mathrm{pH}$ on arsenic sorption and metal leaching}

Fig. 5 shows the effect of solution $\mathrm{pH}$ on sorption of $\mathrm{As}(\mathrm{V})$ and As(III). As shown in Fig. 5, the $\mathrm{As}(\mathrm{V})$ sorption on the $\mathrm{Fe}-\mathrm{Cu}$ binary oxide is very effective under acidic and weak basic conditions. Although higher $\mathrm{pH}$ is not favoring its sorption, the oxide has an $\mathrm{As}(\mathrm{V})$ sorption capacity as high as $39 \mathrm{mg} / \mathrm{g}$ at $\mathrm{pH}$ about 9.1. This may be attributed to the relatively high PZC value (7.9) of the Fe-Cu binary oxide. Generally, As(V) sorption is dependent on $\mathrm{pH}$ and decreases with an increase in solution $\mathrm{pH}$. Similar phenomena were also observed for the sorption of $\mathrm{As}(\mathrm{V})$ onto other iron oxides or iron-containing oxides (Hingston et al., 1972; Ren et al., 2011). The reason is that adsorption of strong acid anions by metal oxides and hydroxides typically decreases with an increasing pH (Stumm, 1996). On the contrary, As(III) sorption gradually increases with the increasing of solution $\mathrm{pH}$ and reaches a maximum at a $\mathrm{pH}$ of approximately 9.1. Then, it decreases slowly with further increase in $\mathrm{pH}$. Adsorption of weak acid anions by metal oxides usually reaches a maximum at $\mathrm{pH}$ values similar to $\mathrm{p} k_{\mathrm{a} 1}$ of the acid (Stumm, 1996). The $\mathrm{p} k_{\mathrm{a} 1}$ of arsenious acid is 9.2. The decrease in $\mathrm{As}$ (III) sorption at $\mathrm{pH}$ over 9.1 may be due to the coulumbic repulsion between As(III) species and the negative surfaces of $\mathrm{Fe}-\mathrm{Cu}$ binary oxide $\left(\mathrm{pH}_{\mathrm{pzc}}=7.9\right)$.

Fig. S2 demonstrates the concentrations of dissolved Fe and $\mathrm{Cu}$ under different pHs. The Fe concentrations are all below $0.1 \mathrm{mg} / \mathrm{L}$ under tested $\mathrm{pH}$ range, which are far below the limit of drinking water standard (USEPA). The leaching of $\mathrm{Cu}$ is serious under acid condition. But its release is very small and the concentrations of $\mathrm{Cu}$ are all below the limit of drinking water of $1 \mathrm{mg} / \mathrm{L}$ at $\mathrm{pH}$ over 6.0. Obviously, the prepared sorbent could be safely used in the majority of water supplies, in which $\mathrm{pH}$ is in a range of 6.5-8.5 (Gu et al., 2005).

\subsection{Influence of coexisting anions on arsenic sorption}

The effects of commonly present anions such as sulfate, bicarbonate, silicate and phosphate in water on arsenic sorption were examined at different concentrations (from 5 to $100 \mathrm{mg}$ / L) and at $\mathrm{pH}$ of $7.0 \pm 0.1$. The results are illustrated in Fig. 6 . The presence of sulfate and bicarbonate does not greatly influence the $\mathrm{As}(\mathrm{V})$ sorption. Only a slight reduction in $\mathrm{As}(\mathrm{V})$ sorption is observed when the coexisting sulfate or bicarbonate concentration is as high as $100 \mathrm{mg} / \mathrm{L}$. However, the present phosphate hinders significantly $\mathrm{As}(\mathrm{V})$ sorption, especially at high concentration levels. The influences of these anions on As(III) sorption are similar to those of $\mathrm{As}(\mathrm{V})$, except for a lower sorption rate. The greatest decrease in $\mathrm{As}(\mathrm{V})$ sorption resulting from the presence of phosphate may be due to the strong competition for the binding sites of the sorbent between phosphate and arsenic. Both phosphate and arsenic are located in the same main group, and the structure of phosphate ion is very similar to that of arsenic ion. Thus, the present phosphate ions might strongly compete with arsenic ions for adsorptive sites on the surface of Fe-Cu binary hydrous oxide.

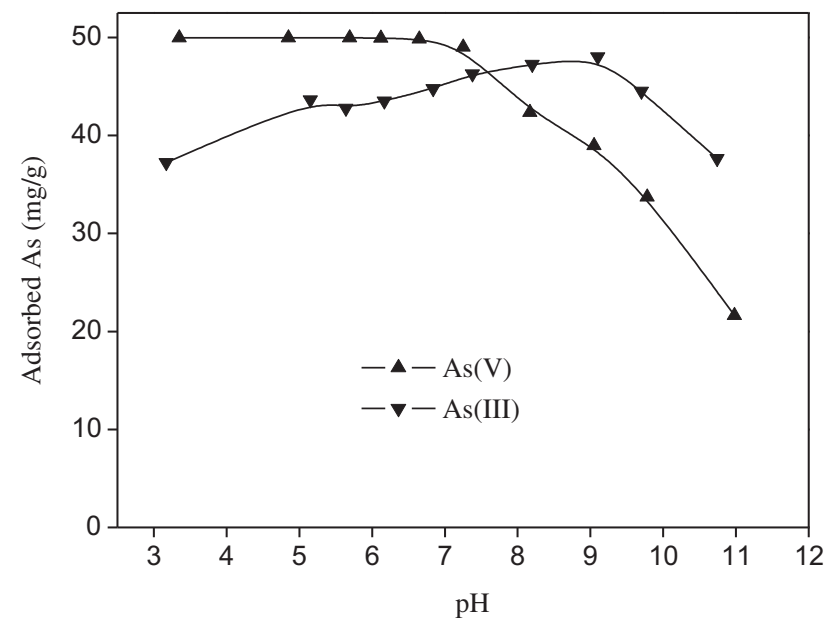

Fig. 5 - Effect of solution $\mathrm{pH}$ on $\mathrm{As}(\mathrm{V})$ and $\mathrm{As}$ (III) sorption by $\mathrm{Fe}-\mathrm{Cu}$ binary oxide. Initial arsenic concentration $=10 \mathrm{mg} /$ $\mathrm{L}$, adsorbent dose $=200 \mathrm{mg} / \mathrm{L}$ and $\mathrm{T}=25 \pm 1{ }^{\circ} \mathrm{C}$. 

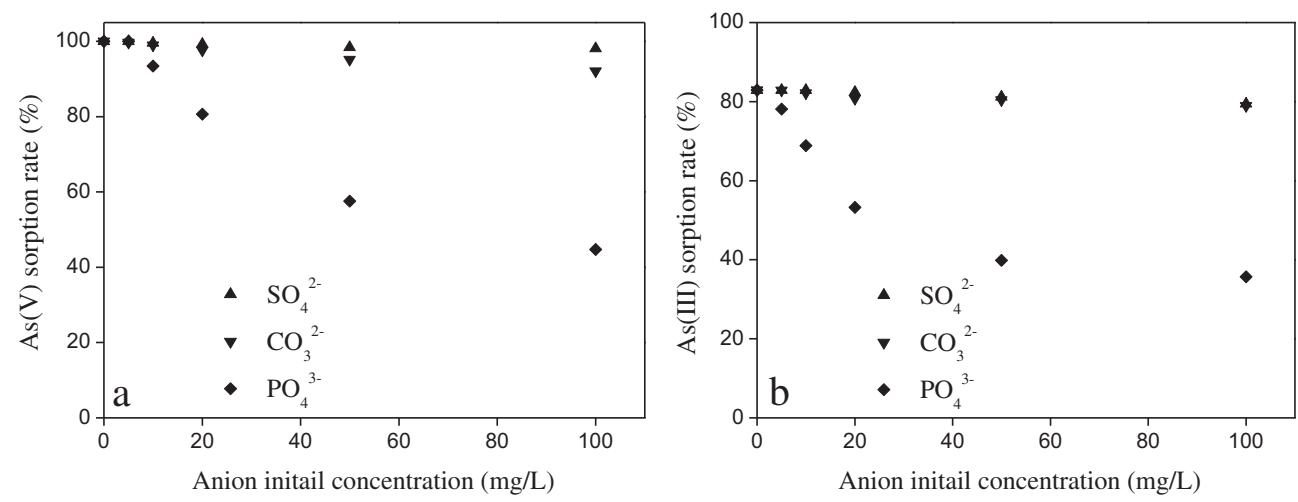

Fig. 6 - Effects of co-existing anions on (a) As(V) and (b) As(III) sorption at different concentrations. Initial arsenic concentration $=10 \mathrm{mg} / \mathrm{L}$, adsorbent dose $=200 \mathrm{mg} / \mathrm{L}, \mathrm{pH}=7.0 \pm 0.1$ and $\mathrm{T}=25 \pm 1{ }^{\circ} \mathrm{C}$.

Although phosphate influences greatly arsenic sorption on the $\mathrm{Fe}-\mathrm{Cu}$ binary oxide at high concentration, it does not significantly hinder arsenic sorption when the phosphate and arsenic concentrations were in the same level. This suggests that the binary oxide has a high sorptive selectivity to arsenic and is able to remove arsenic even at high concentrations of the competing anions used in present work.

\subsection{Analysis of XPS spectra}

To verify the presence of arsenic and determine the oxidation state on the surface, XPS spectra of the Fe-Cu binary oxide before and after reaction with $\mathrm{As}(\mathrm{V})$ or As(III) were collected and analyzed. The results are shown in Fig. 7. New As3d core level peak as well as AsLMM and As3p peaks appeared in the spectra of $\mathrm{Fe}-\mathrm{Cu}$ binary oxide after its reaction with $\mathrm{As}(\mathrm{V})$ or As(III), indicating clearly the presence of arsenic on the surface of the samples.

The As3d core level peaks of the Fe-Cu binary oxide after reaction with arsenic demonstrated in Fig. 8. For the samples reacted with $\mathrm{As}(\mathrm{V})$ and $\mathrm{As}(\mathrm{III})$, the As3d binding energies are 45.4 and $44.3 \mathrm{eV}$, respectively. The binding energy of As3d core level for $\mathrm{As}(\mathrm{V})$ and $\mathrm{As}(\mathrm{III})$ in arsenic oxides are reportedly

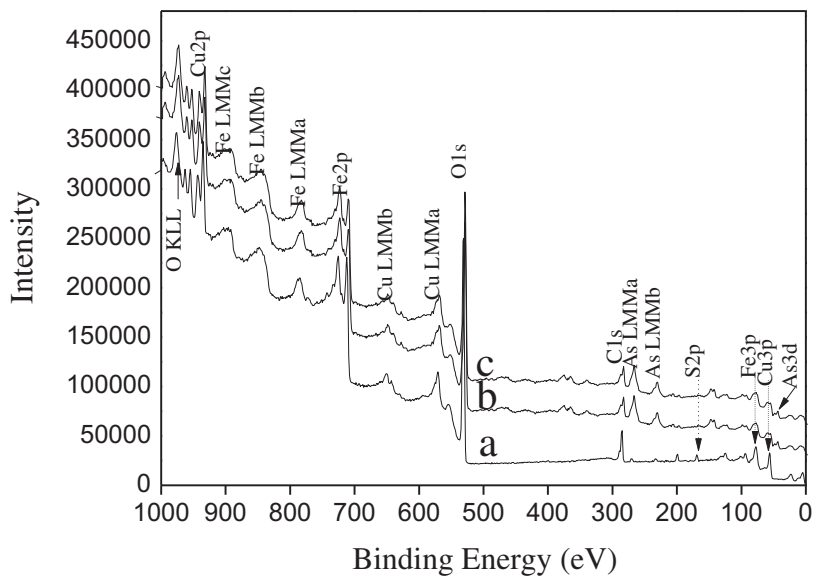

Fig. 7 - XPS spectra of Fe-Cu binary oxide (a) as prepared; (b) after reaction with $\mathrm{As}(\mathrm{V})$; and (c) after reaction with As(III).
45.2-45.6 and 44.3-44.5 eV, respectively (Nesbitt et al., 1998; Ouvrard et al., 2005). Clearly, the arsenic species adsorbed on the surface of the $\mathrm{Fe}-\mathrm{Cu}$ oxide after the reaction with $\mathrm{As}(\mathrm{V})$ and $\mathrm{As}(\mathrm{III})$ still remained as $\mathrm{As}(\mathrm{V})$ and $\mathrm{As}(\mathrm{III})$, respectively. Namely, no change in oxidation state of As(III) was observed during the sorption process. These results are very similar to those found by Ren et al. (2011) in the case of Fe-Zr binary oxide. However, they are different from the results reported by Martinson and Reddy (2009) in the case of pure CuO nanoparticle. They found that As(III) was completely converted to $\mathrm{As}(\mathrm{V})$ after its sorption onto the surface of $\mathrm{CuO}$.

\subsection{Regeneration and reusability of $\mathrm{Fe}-\mathrm{Cu}$ binary oxide}

To evaluate the reusability of the synthetic $\mathrm{Fe}-\mathrm{Cu}$ binary oxide, the adsorption capacity of the composite for arsenic

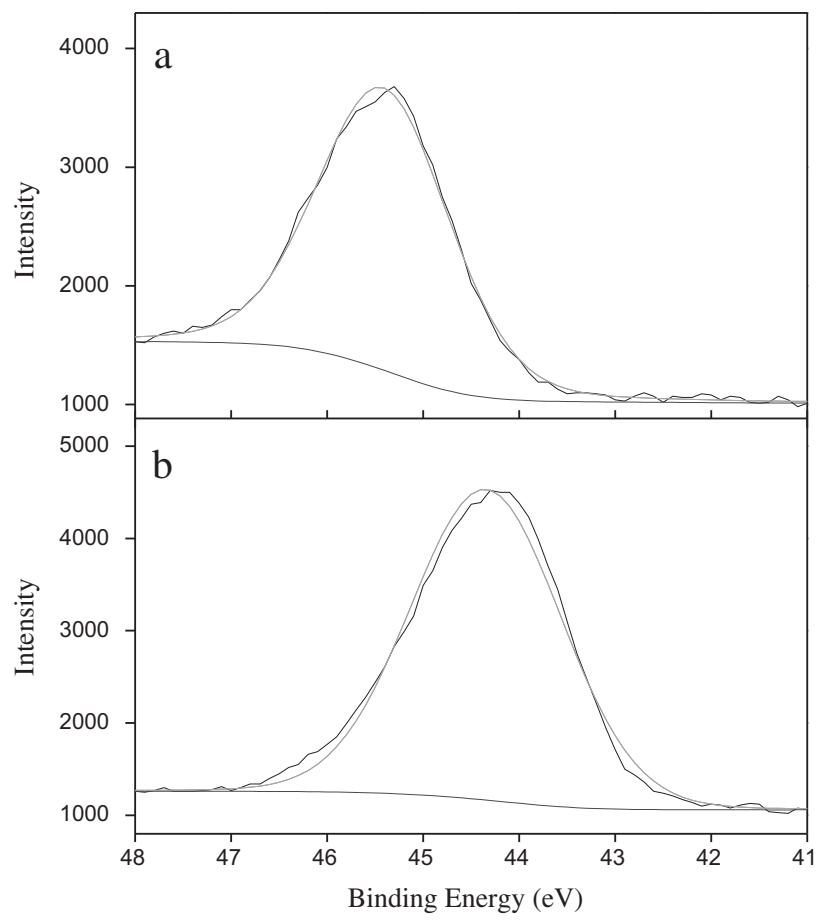

Fig. 8 - As3d core level of the Fe-Cu binary oxide (a) after reaction with $\mathrm{As}(\mathrm{V})$ and (b) after reaction with $\mathrm{As}$ (III). 


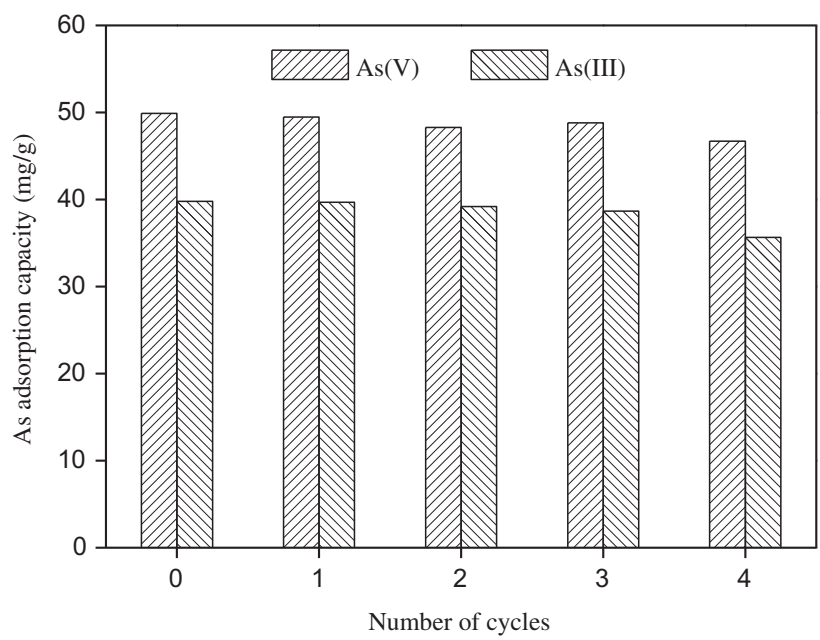

Fig. 9 - Variation of the adsorption capacity of the $\mathrm{Fe}-\mathrm{Cu}$ binary oxide as a function of regeneration cycle number.

after its regeneration has also been studied. These adsorption-regeneration cycles were carried out up to four times. The results obtained are depicted in Fig. 9. The value of cycle 0 corresponds to the adsorption capacity of the fresh $\mathrm{Fe}-\mathrm{Cu}$ binary oxide.

Generally, the adsorption capacity of the $\mathrm{Fe}-\mathrm{Cu}$ binary oxide for arsenic decreases as the number of regeneration cycle increases. However, the decrease was not significant and after the forth regeneration, the reduction in $\mathrm{As}(\mathrm{V})$ and $\mathrm{As}(\mathrm{III})$ adsorption capacity was only $6.2 \%$ and $10.6 \%$, respectively. These results show that the prepared $\mathrm{Fe}-\mathrm{Cu}$ binary oxide could be easily regenerated via $\mathrm{NaOH}$ treatment and has a high durability.

\section{Conclusions}

A novel nanostructured $\mathrm{Fe}-\mathrm{Cu}$ binary oxide was synthesized by a facile coprecipitation method. The synthetic $\mathrm{Fe}-\mathrm{Cu}$ binary oxide is amorphous and 2-line ferrihydrite like. The prepared $\mathrm{Fe}-\mathrm{Cu}$ binary oxide particles are aggregates formed by smaller nanosized particles and are very effective at removing both $\mathrm{As}(\mathrm{V})$ and $\mathrm{As}(\mathrm{III})$ from aqueous solution. The maximal adsorption capacities for $\mathrm{As}(\mathrm{V})$ and $\mathrm{As}(\mathrm{III})$ are 82.7 and $122.3 \mathrm{mg} / \mathrm{g}$ at $\mathrm{pH}$ 7.0, respectively, which outperform most of reported sorbents. The coexisting sulfate and carbonate have no great effect on arsenic removal. However, the presence of phosphate obviously reduces the arsenic removal, especially at high concentrations. Furthermore, the $\mathrm{Fe}-\mathrm{Cu}$ binary oxide could be readily regenerated and repeatedly used. Due to its excellent arsenic removal performance, simple and low-cost synthesis process, and easy regeneration, the $\mathrm{Fe}-\mathrm{Cu}$ binary oxide could be a promising adsorbent for both $\mathrm{As}(\mathrm{V})$ and $\mathrm{As}(\mathrm{III})$ removal from aqueous solution. Further research is currently being performed to granulate the nanostructured $\mathrm{Fe}-\mathrm{Cu}$ binary oxide particles, which could be readily used in fixed beds of water treatment facilities.

\section{Acknowledgments}

The authors acknowledge financial support by National Natural Science Foundation of China (Grant No. 51178453).

\section{Appendix A. Supplementary data}

Supplementary data related to this article can be found at http://dx.doi.org/10.1016/j.watres.2012.11.059.

\section{R E F E R E N C E S}

Cao, A.M., Monnell, J.D., Matranga, C., Wu, J.M., Cao, L.L., Gao, D., 2007. Hierachical nanostructured copper oxide and its application in arsenic removal. The Journal of Physical Chemistry C 111, 18624-18628.

Cullen, W.R., Reimer, K.J., 1989. Arsenic speciation in the environment. Chemical Reviews 89, 713-764.

Dhoble, R.M., Lunge, S., Bhole, A.G., Rayalu, S., 2011. Magnetic binary oxide particles (MBOP): a promising adsorbent for removal of As(III) in water. Water Research 45, 4769-4781.

Dixit, S., Hering, J.G., 2003. Comparison of arsenic(V) and arsenic(III) sorption onto iron oxide minerals: implications for arsenic mobility. Environmental Science \& Technology 37, 4182-4189.

Goddington, K., 1986. A review of arsenals in biology. Toxicological \& Environmental Chemistry 11, 281-290.

Goswami, A., Paul, P.K., Purkait, M.K., 2012. Arsenic adsorption using copper (II) oxide nanoparticles. Chemical Engineering Research and Design 90, 1387-1396.

Gu, Z., Fang, J., Deng, B.L., 2005. Preparation and evaluation of GAC-based iron-containing adsorbents for arsenic removal. Environmental Science \& Technology 39, 3833-3843.

Gupta, K., Ghosh, U.C., 2009. Arsenic removal using hydrous nanostructure iron(III) -titanium(IV) binary mixed oxide from aqueous solution. Journal of Hazardous Materials 161, 884-892.

Hang, C., Li, Q., Gao, S., Shang, J.K., 2012. As(III) and As(V) adsorption by hydrous zirconium oxide nanoparticles synthesized by a hydrothermal process followed with heat treatment. Industrial \& Engineering Chemistry Research 51, 353-361.

Hingston, F.J., Posner, A.M., Quirk, J.P., 1972. Anion adsorption by goethite and gibbsite. Journal of Soil Science 23, 177-192.

Hlavay, J., Polyák, K., 2005. Determination of surface properties of iron hydroxide-coated alumina adsorbent prepared for removal of arsenic from drinking water. Journal of Colloid and Interface Science 284, 71-77.

Hristovski, K.D., Westerhoff, P.K., Crittenden, J.D., Olson, L.W., 2008. Arsenate removal by nanostructured $\mathrm{ZrO}_{2}$ spheres. Environmental Science \& Technology 42, 3786-3790.

Jang, M., Min, S.H., Kim, T.H., Park, J.K., 2006. Removal of arsenite and arsenate using hydrous ferric oxide incorporated into naturally occurring porous diatomite. Environmental Science \& Technology 40, 1636-1643.

Jegadeesan, G., Al-Abed, S.R., Sundaram, V., Choi, H., Scheckel, K.G., Dionysiou, D.D., 2010. Arsenic sorption on $\mathrm{TiO}_{2}$ nanoparticles: size and crystallinity effects. Water Research 44, 965-973.

Kartinen, E.O., Martin, C.J., 1995. An overview of arsenic removal processes. Desalination 103, 79-88.

Kinniburgh, D.G., Syers, J.K., Jackson, M.L., 1975. Specific adsorption of trace amounts of calcium and strontium by 
hydrous oxides of iron and aluminum. Proceedings - Soil Science Society of America 39, 464-470.

Lafferty, B.J., Ginder-Vogel, M., Sparks, D.L., 2010. Arsenite oxidation by a poorly crystalline manganese oxide 1 . Stirredflow experiments. Environmental Science \& Technology 44, 8460-8466.

Lenoble, V., Laclautre, C., Serpaud, B., Deluchat, V., Bollinger, J.C., 2004. As(V) retention and As(III) simultaneous oxidation and removal on a $\mathrm{MnO}_{2}$-loaded polystyrene resin. Science of the Total Environment 326, 197-207.

Li, Z.J., Deng, S.B., Yu, G., Huang, J., Lim, V.C., 2010. As(V) and As(III) removal from water by a Ce-Ti oxide adsorbent: behavior and mechanism. Chemical Engineering Journal 161, 106-113.

Lin, T.F., Wu, J.k, 2001. Adsorption of arsenite and arsenate with activated alumina grains: equilibrium and kinetics. Water Research 35, 2049-2057.

Mandal, B.K., Suzuki, K.T., 2002. Arsenic round the world: a review. Talanta 58, 201-235.

Martinson, C.A., Reddy, K.J., 2009. Adsorption of arsenic(III) and arsenic(V) by cupric oxide nanoparticles. Journal of Colloid and Interface Science 336, 406-411.

Mohan, D., Pittman, C.U., 2007. Arsenic removal from water/ wastewater using adsorbents-A critical review. Journal of Hazardous Materials 142, 1-53.

Nesbitt, H.W., Canning, G.W., Bancroft, G.M., 1998. XPS study of reductive dissolution of $7 \AA$-birnessite by $\mathrm{H}_{3} \mathrm{AsO}_{3}$ with constraints on reaction mechanism. Geochimica et Cosmochimica Acta 62, 2097-2110.

Ouvrard, S., Donato, P., Simonnot, M.O., Begin, S., Ghanbaja, J., Alnot, M., Duval, Y.B., Lhote, F., Barres, O., Sardin, M., 2005. Natural manganese oxide: combined analytical approach for solid characterization and arsenic retention. Geochimica et Cosmochimica Acta 69, 2715-2724.

Patra, A.K., Dutta, A., Bhaumik, A., 2012. Self-assembled mesoporous $\gamma-\mathrm{Al}_{2} \mathrm{O}_{3}$ spherical nanoparticles and their efficiency for the removal of arsenic from water. Journal of Hazardous Materials 201-202, 170-177.

Pena, M.E., Korfiatis, G.P., Patel, M., Lippincott, L., Meng, X.G., 2005. Adsorption of $\mathrm{As}(\mathrm{V})$ and $\mathrm{As}(\mathrm{III})$ by nanocrystalline titanium dioxide. Water Research 39, 2327-2337.

Raven, K.P., Jain, A., Loeppert, R.H., 1998. Arsenite and arsenate adsorption on ferrihydrite: kinetics, equilibrium, and adsorption envelopes. Environmental Science \& Technology 32, 344-349.

Ren, Z.M., Zhang, G.S., Chen, J.P., 2011. Adsorptive removal of arsenic from water by an iron-zirconium binary oxide adsorbent. Journal of Colloid and Interface Science 358, 230-237.
Schwertmann, U., Cornell, R.M., 2000. Iron Oxides in the Laboratory: Preparation and Characterization, second ed. Wiley-VCH, Weinheim.

Scott, K.N., Green, J.F., Do, H.D., Mclean, S.J., 1995. Arsenic removal by coagulation. Journal of the American Water Works Association 87, 114-126.

Sharma, V.K., Sohn, M., 2009. Aquatic arsenic: toxicity, speciation, transformations, and remediation. Environment International 35, 743-759.

Smedley, P.L., Kinniburgh, D.G., 2002. A review of the source, behavior and distribution of arsenic in natural waters. Applied Geochemistry 17, 517-568.

Stumm, W., 1996. Chemistry of the Solid-water Interface. Wiley-Interscience, New York.

U.S. Environmental Protection Agency (online). Drinking water Contaminants. http://water.epa.gov/drink/contaminants/ index.cfm.

Waypa, J.J., Elimelech, M., Hering, J.G., 1997. Arsenic removal by $\mathrm{RO}$ and NF membranes. Journal of the American Water Works Association 89, 102-116.

Xu, Z.C., Li, Q., Gao, S., Shang, J.K., 2010. As(III) removal by hydrous titanium dioxide prepared from one-step hydrolysis of aqueous $\mathrm{TiCl}_{4}$ solution. Water Research 44, 5713-5721.

Yan, X.P., Kerrich, R., Hendry, M.J., 2000. Distribution of arsenic(III), arsenic(V) and total inorganic arsenic in porewaters from a thick till and clay-rich aquitard sequence, Saskatchewan, Canada. Geochimica et Cosmochimica Acta 64, 2637-2648.

Yoon, R.H., Salman, T., Donnay, G., 1979. Predicting points of zero charge of oxides and hydroxides. Journal of Colloid and Interface Science 70, 483-493.

Zhang, G.S., Liu, H.J., Qu, J.H., Jefferson, W., 2012. Arsenate uptake and arsenite simultaneous sorption and oxidation by Fe-Mn binary oxides: influence of $\mathrm{Mn} / \mathrm{Fe}$ ratio, $\mathrm{pH}, \mathrm{Ca}^{2+}$, and humic acid. Journal of Colloid and Interface Science 366, 141-146.

Zhang, G.S., Qu, J.H., Liu, H.J., Liu, R.P., Wu, R.C., 2007a. Preparation and evaluation of a novel Fe-Mn binary oxide adsorbent for effective arsenite removal. Water Research 41, 1921-1928.

Zhang, G.S., Qu, J.H., Liu, H.J., Liu, R.P., Li, G.T., 2007b. Removal mechanism of As(III) by a Novel Fe-Mn binary oxide adsorbent: oxidation and sorption. Environmental Science \& Technology 41, 4613-4619.

Zhang, Y., Yang, M., Dou, X.M., He, H., Wang, D.S., 2005. Arsenate adsorption on an $\mathrm{Fe}-\mathrm{Ce}$ bimetal oxide adsorbent: role of surface properties. Environmental Science \& Technology 39, 7246-7253. 